\title{
The Howie Code for preventing infection in clinical laboratories: comments on some general criticisms and specific complaints
}

\author{
J W HOWIE, C H COLLINS
}

\begin{abstract}
The report of the working party to formulate a code of practice for preventing infection in clinical laboratories and postmortem rooms ${ }^{1}$ was completed in January 1978. Although the code did not appear in print until 12 months later (the report was not published) photocopies of the original report and code were widely circulated and both they and the printed version provoked a good deal of comment, some of which has been expressed in print ${ }^{2-8}$ and some made to us personally.

The working party was disbanded after its report was delivered to the Department of Health and Social Security, and we therefore feel free to express our views, as private individuals, on some of these general criticisms and specific complaints. Together with our own later thoughts and hopes on the report and code, this communication may be regarded as a personal contribution to the necessary and continuing debate on the code, which we naturally welcome.
\end{abstract}

\section{Background to the code}

After the escape of smallpox from the London School of Hygiene in $1973,{ }^{\circ}$ DHSS accepted, as one of the recommendations of the Godber Report on dangerous pathogens, ${ }^{10}$ that a code of practice should be drawn up for preventing infection in clinical laboratories and postmortem rooms. In 1975 a working party was set up to draft such a code, and late in 1978 the code was published. ${ }^{1}$

\section{Edinburgh}

SIR JAMES HOWIE, MD, HON FIMLS, member of the working party which produced the code

The Ashes, Hadlow, Kent, TN11 OAS

C H COLLINS, FIBIOL, FIMLS, member of the working party which produced the code
Why was it necessary to codify good safety precautions? Experienced laboratory workers, especially in microbiology laboratories, knew the dangers of their occupation and assessed them realistically, neither exaggerating the dangers nor treating them with contempt. Nevertheless, in 1957, it had come as a surprise to many that various categories of laboratory workers were from two to nine times more likely to acquire and die of tuberculosis than those in comparable social groups engaged in other occupations. ${ }^{11}$ Some heads of clinical laboratories took appropriate steps to reduce this risk; but many did not. In 1969-70 a dramatic outbreak of hepatitis in an Edinburgh hospital claimed the lives of eight patients and three members of staff. It was shown in a report from the Public Health Laboratory Service $^{12}$ how simple but effective precautions could almost wholly remove a hepatitis risk. Numerous publications on the need for and nature of appropriate safety precautions were available, ${ }^{1314}$ and appropriate recommendations were made in many of the publications. Surveys showed, however, that too many laboratories were still not taking adequate precautions to reduce infection risks. ${ }^{15}$ 16 The concern expressed by many informed workers about the escape of smallpox from the London School of Hygiene in 1973, and the Edinburgh outbreak of hepatitis in 1969-70, combined with mounting public interest to press the conclusion that something stronger than advice and exhortation was required. Hence DHSS's correct decision to have a code of practice. The code was formulated by a working party of 13, all of whom had active experience of laboratory work. A draft was widely distributed for criticism and comments by those who would be affected. All comments received during a period of nine months were carefully considered by the working party. Many-not all-were accepted; and the code, together with a report and recommendations, was sent to DHSS early in 1978. Late in 1978 the code was issued under cover of a departmental circular on priorities and the mode and timing of its implementation. ${ }^{17}$ 
Mandatory provisions of the code and recommendations of the working party

\section{PROVISIONS}

The code classified microbes and materials submitted to clinical laboratories into three main categories: A, identical with the A list of the Dangerous Pathogens Advisory Group, ${ }^{18}$ - that is, pathogens carrying a hazard of epidemics in the general population as well as being dangerous to laboratory staff; B1, pathogens not likely to be dangerous to the general population but requiring special accommodation and precautions for their safe reception and handling by laboratory workers; B2, pathogens requiring special precautions as for those in B1 but not special accommodation; and $C$, organisms and materials not carrying special risks if high standards of laboratory discipline, hygiene, and methods were observed as set out in detail in the code of practice.

The code gave either outlines or detailed requirements on such matters as the selection, training, and duties of safety officers; proper installation, operation, and checking of safety cabinets; methods for dealing safely with blood; reception of specimens; protective clothing; dealing with accidents; handwashing; centrifuges; disposal of specimens; provision of suitable rest rooms; avoidance of mouth pipetting, eating, smoking, or drinking in laboratories; sterilisation and disinfection; supervision of the health of staff; protective immunisations, preemployment radiographs of chest; and monitoring of sickness absences.

\section{FIVE RECOMMENDATIONS}

In transmitting the code to DHSS the working party made five important recommendations, which were not published as part of the code.

(1) Need for full and adequate consultations between client authority and the designers and users of new laboratories and postmortem rooms. Important changes of design were too often made without the prospective users being informed. Attempts to upgrade existing buildings were also to be subject to the same necessary consultation with users.

(2) Assessment of the microbiological safety and suitability of new types of equipment before they were introduced into laboratory and hospital work.

(3) Provision of courses of instruction, on a national scale and to a national standard, for safety officers.

(4) Arrangements to gain information on the working of the code in actual practice and for making such revisions as might be found necessary to keep the code up to date and.workable in laboratories in a reasonably practicable way.

(5) A scheme for notifying all infections possibly acquired in laboratories.

\section{General criticisms}

Laboratory workers, not surprisingly, were not unanimous in welcoming even the idea of a code of practice. The best among them had already assessed the potential dangers of their own laboratories and taken serious care to prevent lapses of discipline and method. Unfortunately, however, the gap between the best and the average was too wide; and the public and professional concern about the gap between the average and the worst was too well justified to be ignored. Heggie ${ }^{8}$ emphasised that good advice was available in 1972 and was followed by many; but, as Harrington and Shannon found, ${ }^{16}$ it was also ignored by too many.

Concern expressed by others such as Simmons ${ }^{6}$ and by Taylor and his colleagues ${ }^{7}$ probably arose from the unwisdom contained in some documents from the Health and Safety Executive $^{4}$ and from inspections of laboratories carried out by health and safety officers insufficiently aware of the exact realities of infection risks and of sound laboratory discipline and methods. Their ideas on what was reasonably practicable were too often unrealistic.

DHSS's Interim Advisory Committee on the code and its implementation has now issued its first deliverance, ${ }^{19}$ and it is our hope that further communications from this source will quickly follow and ensure that-as firmly recommended by the working party-the code will be tested in practice and kept up to date so that, if and when the time eventually comes to give it full statutory authority (see ref 20 on this issue), it will be based on what has been found to be both workable and necessary. Meantime the code has already been welcomed by numerous colleagues as a helpful guide to good safety practices and as having provided an effective instrument for stimulating administrators to find money, despite spending cuts, for many long resisted but essential improvements in laboratory accommodation, staff, and equipment.

\section{Specific complaints}

(1) An immediate complaint concerns difficulty in securing a copy of the printed code. It was intended that every NHS laboratory worker should have a copy, but in some places they do not seem to be available. Whether this is due to printing difficulties or to a cumbersome system of distribution through the several tiers of NHS administration we do not know, but it seems clear that history is repeating itself. The same problem affected the distribution of the booklet Safety in Pathology Laboratories $^{13}$; and even as late as 1975 , three years after publication and after three circulars had been sent out by DHSS, some laboratories had still not received copies. With hindsight it would seem sensible to distribute material of such personal importance to laboratory workers through their professional bodies which can estimate accurately the numbers required and which have well-organised means of circulation.

There have also been justified comments on the misprints in the code as finally printed. Members of the working party were not invited to read a proof of this edition, as we had hoped and expected.

(2) The composition of the working party has been questioned by several people, including Brownhill, ${ }^{2}$ who wondered if practitioners were adequately represented. A study of the list of members should remove these doubts. All of those named were active laboratory workers. Moreover, during the visits to many laboratories made by one of us (CHC) discussions were had with over 100 bench-workers on their immediate problems and what steps they took to reduce them. In this way a body of opinion of practical precautions was assembled and as stated earlier ${ }^{21}$ the code reflected not merely what the working party considered practicable but what was actually being done in the laboratories. (3) During the consultations with many professional bodies and individuals before publication, and since that time, we have been asked why the code was confined to microbiological hazards. Chemical and physical hazards are not mentioned in the Howie Code; and it has been claimed that too much attention to microbiological problems may reduce care in these other, equally important, areas. The reason for excluding these matters was that the working party necessarily kept within its terms of reference which were "To formulate a code of practice for the prevention of infection in clinical laboratories and postmortem rooms." In fact there are already excellent codes of practice for other laboratory activities. ${ }^{22-24}$ There are also building, engineering, and architectural specifications that cover such things as piped gases, ventilation, and the storage of hazardous substances. ${ }^{25}$

(4) The list of pathogens in category $\mathbf{A}$ given in the code has also been questioned. This list was not made by the working party: it was received from the Dangerous Pathogens Advisory Group $^{18}$; and if members of our working party had private misgivings it would not have been proper for them to have made alterations for the code of practice they formulated. 
(5) The continuing importance of tuberculosis as a laboratoryacquired infection cannot be overestimated and needs constant reiteration, ${ }^{15}$ but the position with hepatitis has somewhat changed. The working party was sure that the risk was in the course of being understood and coped with; but strong advocacy of the need to keep the precautions in being until this was certain was sufficient to persuade the members that the precautions should stand at that stage. To have insisted on the contrary line would have led to a minority report. Recent findings ${ }^{26} 27$ and, again, hindsight have persuaded $\mathrm{us}^{28}$ that hepatitis $\mathrm{B}$ virus should now belong not to category B2 but to category $C$, thus bringing it into line with informed American opinion. ${ }^{29}$.It should be remembered, however, that the techniques prescribed for handling category $\mathrm{C}$ material in this code of practice are a great advance on those in common use in some laboratories.

(6) The inclusion of Salmonella typhi in category B has invoked comment. It has been wrongly supposed by some people that the category $B$ pathogens were all thought by the working party to be hazardous because they were associated with air-borne infections. Most of the agents listed are conveyed by the airborne route, but we were well aware that $S$ typhi is an alimentary infection. We put it in category B because it is often treated far too casually, as in its use, for example, as the test organism in the Rideal-Walker test. If $S$ typhi were to be retained for this purpose, which we should deplore as unnecessary even if international agreement for change is hard to negotiate, it must certainly be regarded as an organism that causes a very serious infection, and it should therefore be treated with the care due to a category B pathogen. In the United States, since 1977, there have been 19 laboratory-associated infections, ${ }^{30}$ which confirms the belief of the working party that this organism should be handled with special precautions in special accommodation.

(7) Arguments, for instance, that of Brownhill, ${ }^{2}$ that decontamination of centrifuges will necessitate the supply of large numbers of these machines are wrongly based. If the centrifuges are properly maintained and used correctly there will be fewer accidents and less need for decontamination. (At the Dulwich laboratory there has been one accident concerning pathogens in five years.) Simple cleaning with disinfectant and daily inspection take only a few minutes.

(8) As for complaints about the use of the Coulter Counter and automated chemistry equipment, the techniques described are based on observations made in several busy laboratories-although, to be quite fair, they were laboratories in which infections of one kind or another had occurred or were feared.

(9) The requirement to carry medical contact (NOT ID) cards has drawn criticism, but it does not seem to worry those who habitually 'do so, along with allergy cards, credit cards, driving licence, and AA and other membership cards. The requirement is not really a cause for being anxious about the premature realisation of George Orwell's fear for the future.

(10) Certainly the code has generated a great deal of excitement and activity; but this is welcome. Not all those who have been critical realise that there are laboratories where standards have been allowed to fall so low that management quite rightly fears a visit by an inspector from the Health and Safety Executive. If all laboratories were as good, and all staff as sensible, as the best we have seen there would have been no need for the code; but several reports and publications ${ }^{15}{ }^{31}$ and the intense public concern over the Birmingham 1978 episode show that DHSS simply had no alternative to issuing a code of practice.

(11) Of course, there were two hazards inherent in the code itself: that it would become a tool for militants and a vehicle for managers, to the detriment of the safety of the staff. Both have happened; people have been frightened into declining appointment as safety officers; some have demanded money for doing very little more than their usual day's work; and others have invented new titles and more jargon. For none of this was the working party responsible. Fortunately, in many laboratories, up and down the country, dedicated safety officers are quietly at work and are doing a very good job.

(12) We are quite impenitent about the use of the word "must."
It allowed the really important hazards and precautions to be identified. ${ }^{21}$ Experience with other codes had shown that "should" was usually interpreted as "need not."

(13) The code was never intended to be the final word. The working party advocated keeping it up-to-date in the light of experience and indeed DHSS and a number of other organisations have set up committees and groups of varying experience (and expertise) to look at the code as it stands, to refine it, and to look at its interpretation by HSE inspectors and its relevance or otherwise to laboratories for which it was not intended.

\section{Priorities and hopes}

The working party identified two priorities: (1) the prevention of tuberculosis, and (2) the prevention of hepatitis. The DHSS circular on implementation wisely added a third-namely, (3) the need to appoint and train safety officers and educate all concerned in medical work-not only those in laboratories-on the importance of safety precautions. We agree with that advice but would emphasise that the training of safety officers must be to nationally agreed standards. Some courses that are meantime being offered are not only insufficient but actually in danger of misleading. It is of paramount importance that these courses should be good enough because real safety against infection risks is proportional to the awareness that all members of a laboratory have of the real nature of the materials they are handling. There must be neither contempt for nor exaggerated fears of infection risks; and only adequate training and learning from experienceincluding the experience of others-can ensure this. If we had our job to do again we should add a fourth priority-(4) that the staffing and accommodation of laboratories must be adequate for the work load accepted by the laboratory. Overcrowded, overcommitted laboratories are a danger.

It is our hcpe that this code shall be properly assessed in practice, and amended as may be found necessary before it is given officially approved status. Meantime, however, we believe that it is a fair summary of what current experience has judged to be "reasonably practicable"- a phrase regarded as of crucial importance by informed lawyers.

Requests for reprints to $\mathrm{C} \mathrm{H}$ Collins, The Ashes, Hadlow, Kent, TN11 OAS.

\section{References}

${ }^{1}$ Department of Health and Social Security. Code of practice for the prevention of infection in clinical laboratories and postmortem rooms. London : HMSO, 1978.

${ }^{2}$ Brownhill CB. The Howie Report. Med Tech Sci 1979;12:46.

${ }^{3}$ Freeman R, Ingham HR. Dangerous pathogens and the HSE. Lancet 1979 ;ii:1134.

4 Anonymous. Dangerous pathogens-more thoughts from the HSE. Lancet 1979;ii:1004.

${ }^{5}$ Lea DJ, Ward DJ. Safety in the hospital laboratory. Lancet 1979 ;ii:1083.

6 Simmons NA. Dangerous pathogens and safety at work. Lancet 1979 ;ii: 1194-5.

7 Taylor CED et al. Laboratory safety. Lancet 1980;1:101.

${ }^{8}$ Heggie JC. Laboratory safety. Lancet 1980;1:210.

- Department of Health and Social Security. Report of the committee of inquiry into the smallpox outbreak in London, March and April 1973. Cmnd 5626. London: HMSO, 1974. (Cox Committee Report.)

${ }^{10}$ Department of Health and Social Security. Report of the working party on the laboratory use of dangerous pathogens. Cmnd 6504. London: HMSO, 1975. (Godber Report.)

${ }^{11}$ Reid DD. Incidence of tuberculosis among workers in medical laboratories. Br Med F 1957;ii:10-4

12 Public Health Laboratory Service. Decrease in the incidence of hepatitis in dialysis units associated with the prevention programme. $\mathrm{Br} \mathrm{Med} \mathcal{F}$ 1974 ;iv:751-4.

${ }^{13}$ Department of Health and Social Security. Safety in pathology laboratories. London: DHSS, 1972

14 Collins CH, Hartley EG, Pilsworth R. The prevention of laboratory acquired infection. London: HMSO, 1974. (Public Health Laboratory Service Monograph No 6.)

15 Harrington JM, Shannon HS. Incidence of tuberculosis, hepatitis, brucellosis, and shigellosis in British medical laboratory workers. Br Med F 1976; :759-62. 
${ }^{16}$ Harrington JM, Shannon HS. Survey of health care in British medical laboratory workers. $\mathrm{Br} \mathrm{Med} \mathcal{F} 1977 ; \mathrm{i}: 626-8$.

17 Department of Health and Social Security. Health Circular HC(79)3. London: DHSS, 1979.

18 Department of Health and Social Security. Control of laboratory use of pathogens very dangerous to humans. London: DHSS, 1976.

19 Department of Health and Social Security. Interim Advisory Committee on Safety in Clinical Laboratories. Bulletin No 1, January 1980 (G/H118) 165).

${ }^{20}$ Rankine AD. Laboratory safety. Lancet 1979,ii:1244.

21 Howie Sir James. Reducing infection risks in clinical laboratories. Med Tech Sci 1979;12:23-5.

${ }^{22}$ Royal Institute of Chemistry. Code of practice for chemical laboratories. London: RIC, 1976.

${ }^{23}$ University of Manchester Institute of Science \& Technology. Safety Manual. Manchester: UMIST, 1973.

${ }^{24}$ Collins CH. Safety in pathology laboratories: bibliographies. London: Institute of Medical Laboratory Sciences, 1976 and 1978.
25 Department of Health and Social Security. Hospital building note. No 15: Pathology laboratories. London: DHSS, 1973 (new edition in preparation).

${ }^{26}$ Grist NR. Hepatitis in clinical laboratories 1975-6. $\mathcal{F}$ Clin Pathol 1978;31: 415-7.

27 Public Health Laboratory Service, unpublished. Comm Dis Rep 79/48; 1979.

${ }^{28}$ Collins CH. Safety on the cheap. Med Lab World 1979 ;3:14-9.

29 United States Department of Health Education and Welfare. Classification of etiologic agents on the basis of hazard. Atlanta: Centre for Disease Control, 1974

${ }^{30}$ Center for Disease Control. Laboratory-associated typhoid fever. Morb Mort Wkly Rep 28/44; Nov, 1979.

31 Pike RM. Laboratory associated infections : summary and analysis of 3921 cases. Health Lab Sci 1976;13:105-14.

(Accepted 19 February 1980)
Our patient, a 46-year-old radio technician, became critically ill on 2 January 1979 and started a $25000 \mathrm{~km}$ journey by air under special care. An Ilyushin-14 had crashed on take-off at the Soviet Antarctica base at Molodezhnaya (67.45 S, 46.00 E) on the Prince Olaf Coast of Enderby Land. Three crew members were killed, four had fractured legs and one a severe head injury, and 11 escaped unharmed. In Antarctica the various scientific stations have doctors and medical equipment, but there are limits to what can be managed on that harsh continent. The sole air base for external communications is at McMurdo (77.51 S, 166.37 E) with an ice runway that functions only in the southern summer. The US Antarctic Program with Operation Deep Freeze has servicing flights with military aircraft, jet Starlifter, and turboprop Hercules with skis between there and Christchurch, New Zealand, some $3500 \mathrm{~km}$ away. None of the aircraft available in Antarctica had the capacity to take the injured from Molodezhnaya to McMurdo $(2900 \mathrm{~km})$. At the request of the Soviet Government the US Navy sent a Hercules with relief crews and medical teams from New Zealand to McMurdo to Molodezhnaya and return, $11500 \mathrm{~km}$ in 29 hours, with two refuelling stops in Antarctica. As there is a neurosurgical unit in Dunedin we received the unconscious man three days after the accident.

\section{Dunedin at work}

The patient was deeply unconscious with a right hemiplegia and in considerable respiratory distress. He also had fractured ribs and a mediastinal haematoma. A transfemoral arch aortogram excluded an intracranial haematoma and mediastinal vessel damage. He was nursed in the intensive care unit, and a tracheostomy with controlled ventilation was needed. Eventually

Department of Surgery, University of Otago Medical School, and Neurosurgical Unit, Dunedin Hospital, Dunedin, New Zealand R G ROBINSON, CHM, FRCs, professor of neurosurgery HELEN E WILLIAMS, RN, charge nurse his condition stabilised-a chronic vegetative state with a right hemiplegia. The tracheostomy could not be dispensed with owing to feeble coughing, and suction might be needed several times an hour. Feeding was by nasogastric tube, and there was an indwelling urethral catheter. His weight was $90 \mathrm{~kg}$ and height $1.78 \mathrm{~m}$. After six weeks there was little further improvement, and we were asked to plan his transfer to Moscow by commercial aircraft.

The plan was to fly by Air New Zealand (ANZ) from Dunedin via Auckland to Singapore and there pick up an Aeroflot connection to Moscow. Minimum requirements necessitated stopovers of at least 24 hours at Auckland and Singapore, with hospital special care facilities available. A stretcher and a generous supply of oxygen were to be available in all aircraft and he would be accompanied by a doctor and a nurse, who were to have hotel accommodation at stopovers. A day was set after which the patient would be ready to travel. We would accompany the patient to Singapore and offered to go the whole way to Moscow if desired by the Soviet Government.

Commercial airlines provide facilities for the transport of invalids but the care of the patient is the total responsibility of the accompanying team. All the nursing requirements during 10 hours in the special-care ward were noted, as this was the flight time between Auckland and Singapore. The major problem was respiratory care, and constantly available suction had to be provided not only in flight but for the ground transfers. We had seen a rechargeable battery-powered suction apparatus but it was not available to us. In the event this was just as well, as the use of battery-driven equipment contravenes many commercial aircraft regulations, although equipment can be connected up to the electrical systems of the aircraft. Instead we obtained a foot-operated Ambu sucker. This turned out to be ideal; it could be used everywhere without reference to other power sources, besides having excellent suction. An Ambu bag was obtained in case the patient had to be respirated. The necessary medical certificates were supplied to Air New Zealand. A team was selected, with reserves if needed; the members were known to be physically fit from recent performance and thought to be in possession of their wits. 